\title{
Down-Regulation of GKN1 in Gastric Cancer Is Not Associated with the RUNX3 Expression
}

\author{
Chiara Stella Di Stadio ${ }^{*}$, Filomena Altieri ${ }^{*}$, Antonella Federico ${ }^{1 *}$, Giuseppina Miselli1, \\ Antonello Niglio², Maurizio De Palma², Emilia Rippa" ${ }^{1 \#, ~ P a o l o ~ A r c a r i 1,3 \# ~}$ \\ ${ }^{1}$ Department of Molecular Medicine and Medical Biotechnology, University of Naples Federico II, Naples, Italy \\ ${ }^{2}$ Hospital A. Cardarelli, Naples, Italy \\ ${ }^{3}$ CEINGE, Advanced Biotechnology Scarl, Naples, Italy \\ Email:" arcari@unina.it, "emilia.rippa@unina.it
}

How to cite this paper: Di Stadio, C.S., Altieri, F., Federico, A., Miselli, G., Niglio, A., De Palma, M., Rippa, E. and Arcari, P. (2017) Down-Regulation of GKN1 in Gastric Cancer Is Not Associated with the RUNX3 Expression. Journal of Biosciences and Medicines, 5, 80-90.

https://doi.org/10.4236/jbm.2017.511009

Received: October 12, 2017

Accepted: November 25, 2017

Published: November 28, 2017

Copyright $\odot 2017$ by authors and Scientific Research Publishing Inc. This work is licensed under the Creative Commons Attribution International License (CC BY 4.0).

http://creativecommons.org/licenses/by/4.0/

(c) () Open Access

\begin{abstract}
Gastrokine 1 (GKN1) is a gastric mucosal protein highly expressed and secreted in normal individuals but during Helicobacter pylori infection or in gastric carcinogenesis it is strongly down-regulated or totally absent. In gastric cancer, the GKN1 gene is silenced through an epigenetic mechanism most likely mediated by a transcription factor that promotes on GKN1 promoter the activity of the enzymes SUV39H1 and HDACs. Because RUNX3 is a potential candidate in the regulation of molecular carcinogenesis process of stomach cancers, we tried to assess if RUNX3 could be involved in GKN1 down-regulation in GC. 17 paired of non-tumoral and tumoral surgical specimens from patients with gastric cancer were analyzed for GKN1 and RUNX3 by Western blotting and chromatin immunoprecipitation (Chip) assays. The overall results indicated that RUNX3 expression was not associated with the down-regulation of GKN1. The expression levels of RUNX3 in non-tumoral and tumoral samples suggest that RUNX3 does not act as a tumor suppressor but that it might play a complex oncogenic role in gastric cancer cells.
\end{abstract}

\section{Keywords}

Gastrokine 1, Gastric Cancer, Epigenetics, RUNX3, Tumor Suppressor

\section{Introduction}

Gastrokine 1 (GKN1) or $18 \mathrm{kDa}$ Antrum Mucosal Protein (AMP18) is important

^Those authors equally contribute to the work. 
for maintaining the physiological function of the gastric mucosa [1] [2] [3]. However, the GKN1 expression is down-regulated or totally absent in gastric tumor tissues and derived cell lines [4] [5]. Moreover, its over-expression in gastric cancer (GC) cells induces apoptosis, thus suggesting a possible role as a tumor suppressor [6]. The inactivation of GKN1 gene in GC seems to be correlated to epigenetic mechanisms like histone modification that could contribute to its down-regulation. In fact, chromatin immunoprecipitation assays for the trimethylation of histone 3 at lysine 9 (H3K9triMe) and its specific histone-lysine N-methyltransferase (SUV39H1), performed on human specimens of normal and cancerous gastric tissues, showed that GKN1 down-regulation in GC tissues was associated with high levels of H3K9triMe and with the recruitment of SUV39H1 to the GKN1 promoter. These findings suggested that an epigenetic transcriptional complex could negatively regulate $G K N 1$ expression in gastric tumors [7].

The $R U N X$ family (mammalian Runt-related genes) [8] of transcription factors plays an important role during normal development but appears deregulated in neoplasias. This family is composed of three members, $R U N X 1 / A M L 1$, $R U N X 2$ and RUNX3 [9] coding for related proteins with DNA binding properties. RUNX3 is the best characterized of the three family members. It has been described as a tumor promoter or suppressor; however, conflicting results and opinions on its role in same cancer reflect a possible complex role in oncogenesis [10]. In fact, $R U N X 3$ is actually not acknowledged as tumor suppressor gene (TSG). Moreover, scientific reports show that RUNX3 is not expressed in normal gastric epithelium [11] [12], that $R U N X 3$ mutations and $1 \mathrm{p} 36$ deletions are not frequent in GC [13] [14] [15] [16], that $R U N X 3$ promoter methylation is not relevant to its declared TSG function [17], and that RUNX3 is not associated with familial GC or with increased risk of GC. Juxtapose to these outcomes, RUNX3 seems to be overexpressed in several cancers including GC [18] [19] [20] [21], it can promote malignancy and its activation is essential for the proliferation of EBV-transformed B cells [10]. Therefore, considering that RUNX3 could represent a potential candidate in the molecular carcinogenesis process of stomach cancers, we decided to investigate whether RUNX3 could play a role in $G K N 1$ gene inactivation. Here we report by Western blotting that the expression of RUNX3 in non-tumoral and tumoral samples obtained from patients owing GC was not correlated to the down-regulation of GKN1. Moreover, chromatin immunoprecipitation (ChIP) assays also showed the non-association of RUNX3 to the down-regulation of GKN1. These data denoted that RUNX3 might be in GC an oncogene [9] [10] [11] [12] rather than a tumor suppressor [10].

\section{Materials and Methods}

\subsection{Materials}

Mouse GKN1 monoclonal antibody (M01), clone 2E5, was purchased from Abnova (Taipei, Taiwan). Mouse monoclonal to RUNX3 antibody [ab40278] was 
from Abcam (Cambridge, MA, USA). Mouse $\alpha$-Tubulin monoclonal antibody (B7) was from Santa Cruz Biotechnology (Dallas, TX, USA).

\subsection{Human Tissues and Western Blotting}

Patients with GC were recruited at Hospital A. Cardarelli, Naples, Italy. Patients were interviewed for smoking habit, alcohol intake and chronic use of drugs. Hospital Pathologist carried out the dissection of non-tumor and tumor tissues during surgery. GC was staged and graded according to the American Joint Committee on Cancer criteria [22]. The characterization of the non-tumoral gastric mucosa was made by the hospital pathologist from the comparison between the macroscopic aspects of normal tissue versus the tumoral one [23], and from our finding clearly indicating that GKN1, highly expressed in gastric non-tumoral tissues, was strongly down-regulated or totally absent in GC tissues [4]. The University of Naples Federico II Ethics Committee (Comitato Etico Università Federico II) approved this study (protocol number 34/15) [23].

Proteins from cell extracts (about $20 \mu \mathrm{g}$ ) were detected by Western blotting with mouse anti-GKN1 at 1:500, mouse anti-RUNX3 and anti- $\alpha$-Tubulin at 1:1000 dilution. Gel bands were detected using the enhanced chemiluminescence detection kit (SuperSignal West Pico).

\subsection{Chromatin Immunoprecipitation (ChIP) Assay}

Non-tumoral and tumoral tissues were cut into small pieces using a scalpel blade and disaggregate using a Dounce homogenizer to get a homogeneous suspension. Cellular suspension was collected by centrifugation at $2000 \mathrm{rpm}$ at $4^{\circ} \mathrm{C}$ for 10 minutes and then suspended in $6 \times$ volume of cell lysis buffer $[5 \mathrm{mM}$ piperazine-N,N'-bis (2-ethane sulfonic acid) (PIPES) pH 8.0, $85 \mathrm{mM} \mathrm{KCl}, 0.5 \% \mathrm{NP}-40]$ plus phenylmethylsulfonyl fluoride (PMSF) $(1 \mathrm{mM})$ and trypsin inhibitor (10 $\mu \mathrm{g} / \mathrm{mL}$ ) as protease inhibitors. The suspension was then incubated on ice for 15 minutes and lysed using a Dounce several times. Nuclei were collected at 5000 $\mathrm{rpm}$ at $4^{\circ} \mathrm{C}$ for 10 minutes and the pellet was suspended in $5 \times$ volume of nuclei lysis buffer (50 mM Tris- $\mathrm{HCl} \mathrm{pH}$ 8.1, $10 \mathrm{mM}$ EDTA, 1\% SDS) plus the same protease inhibitors as the cell lysis buffer. The solution was incubated on ice for 20 minutes and subsequently froze and thawed in liquid nitrogen 2 times to aid in nuclear lysis. After centrifugation at $5000 \mathrm{rpm}$ at $4^{\circ} \mathrm{C}$ for 10 minutes, the obtained chromatin was sonicated according to the procedure already described [24]. Samples were subjected to immunoprecipitation (IP) with the specific antibody against RUNX3. qRT-PCR was performed as described [7].

\subsection{Statistical Analyses}

Statistical analysis was made by two-tailed paired Student's t-test using KaleidaGraph 4.1.1 software. The intensity of Western blot bands was evaluated with ImageJ $2.0 .0-R C-43 / 1.51 \mathrm{k}$ software. Data are reported as means \pm standard deviation (SD). The significance was accepted at the level of $p<0.05$. 


\section{Results and Discussion}

\subsection{RUNX3 and GKN1 Expression Levels in Non-Tumoral and Tumoral Tissues}

Previously, we showed that epigenetic mechanisms leading to the inactivation of GKN1 gene play a key role in the multi-step process of gastric carcinogenesis. We propose a model in which a transcription factor might functions as a negative regulator by recruiting on the GKN1 promoter SUV39H1 and HDACs to induce histone methylation and deacetylation, respectively thus resulting in $G K N 1$ inactivation (Figure 1). We also found that treatment of gastric cancer cell line with trichostatin A (TSA) strongly enhances the expression of GKN1 mRNA. Therefore, the loss of GKN1 function contributes to malignant transformation and proliferation of gastric epithelial cells in gastric carcinogenesis. Because the RUNX family of transcription factors plays pivotal roles during normal development and in gastric neoplasias, we tried to highlight if RUNX3 could be involved in GKN1 down-regulation during gastric carcinogenesis.

We first analyzed the expression level of GKN1 in twelve paired samples of non-tumoral $\left(\mathrm{N}_{1}-\mathrm{N}_{12}\right)$ and tumoral $\left(\mathrm{T}_{1}-\mathrm{T}_{12}\right)$ gastric tissues taken from 12 patients after surgery. Tissue $\mathrm{T}_{1-2}$ and $\mathrm{T}_{7-8}$ and $\mathrm{T}_{10-11}$ showed a poorly differentiated adenocarcinoma of diffuse type, $\mathrm{T}_{3}-\mathrm{T}_{4}$ and $\mathrm{T}_{9}$ showed a poorly differentiated adenocarcinoma of intestinal type, $\mathrm{T}_{5}-\mathrm{T}_{6}$ showed a moderately differentiated adenocarcinoma of intestinal type, finally, $\mathrm{T}_{12}$ showed a poorly differentiated adenocarcinoma with a neuroendocrine expression of unspecified type. The clinic pathologic characteristics of GC patients are reported in Table 1 . The peritumoral areas of intestinal type GC showed a variable degree of gastric atrophy with diffuse intestinal metaplasia, while the peritumoral areas of diffuse-type GC showed a variable degree of non-dysplastic inflammation.

Figure 2 (panels A B and C) shows the expression profiles of GKN1 in twelve paired non-tumoral and tumoral tissues evaluated by western blotting (WB) using anti-GKN1 antibody. Compared to non-tumoral tissues, down-regulation of

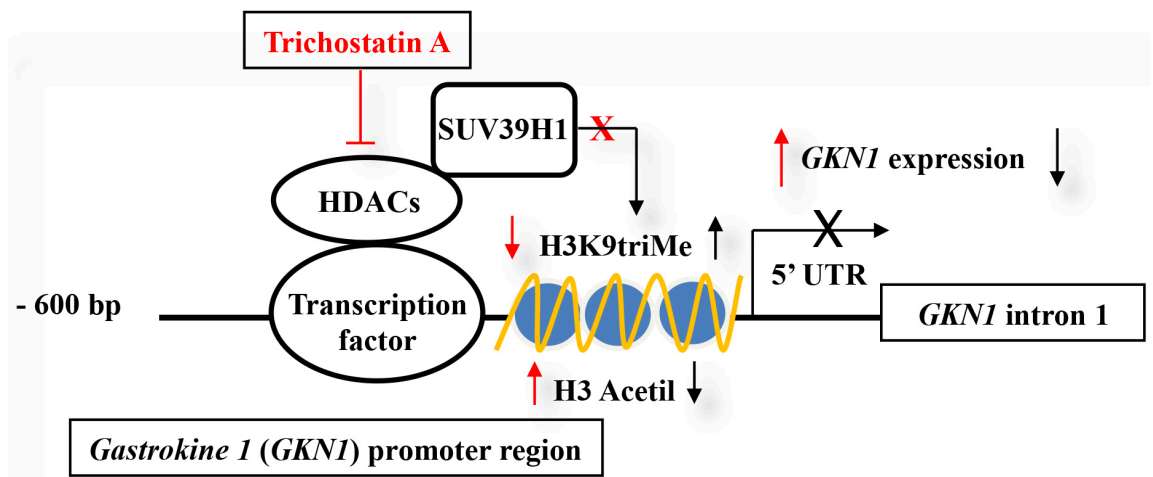

Figure 1. GKN1 gene inactivation proposed mechanisms. A hypothetical transcription factor acts as a negative regulator by enrolling both SUV39H1 and HDACs to the GKN1 promoter thus inducing histone deacetylation and H3K9triMe methylation. Trichostatin A (TSA), an HDACs inhibitor, down-regulated H3K9triMe methylation thus resulting in GKN1 mRNA re-expression [7]. 


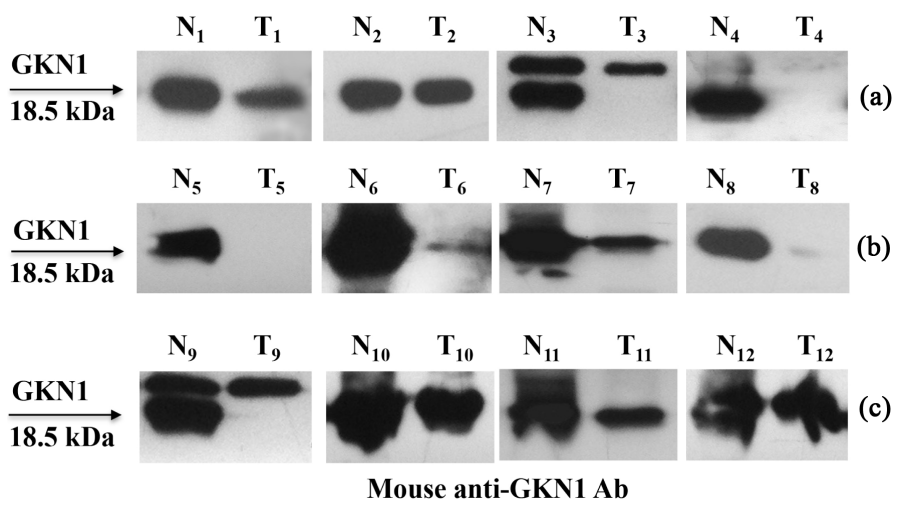

Figure 2. GKN1 expression levels in human gastric tissues. ((a), (b) and (c)) Western blot of tissue extracts analyzed in paired non-tumoral $\left(\mathrm{N}_{1}-\mathrm{N}_{12}\right)$ and tumoral $\left(\mathrm{T}_{1}-\mathrm{T}_{12}\right)$ human gastric samples, respectively, using mouse anti-GKN1 antibody $(\mathrm{Ab})$.

Table 1. Clinical and histopathological characteristics of gastric cancer patients.

\begin{tabular}{lc}
\hline \multicolumn{1}{c}{ Variable } & n. 17 \\
\hline Age at surgery (yrs) & $63 \pm 15$ \\
Mean \pm SD & $32-78$ \\
Range & $8 / 9$ \\
Sex M/F & \\
Tumor type & 6 \\
Intestinal & 6 \\
Diffuse & 5 \\
Unspecified & \\
Stomach region & 5 \\
Antrum & 8 \\
Corpus-Fundus & 4 \\
Not defined & $17(100 \%)$ \\
Grade of differentiation & $3(17.6 \%)$ \\
Moderate & $14(82.4 \%)$ \\
Poor & \\
Stage & \\
Early & \\
Advanced & $(0 \%)$ \\
\hline
\end{tabular}

GKN1 was detected in $\mathrm{T}_{1}, \mathrm{~T}_{2}, \mathrm{~T}_{6}, \mathrm{~T}_{7}, \mathrm{~T}_{10}, \mathrm{~T}_{11}$ and $\mathrm{T}_{12}$ tumoral tissues whereas, in the remaining tumoral specimens $\left(\mathrm{T}_{4}, \mathrm{~T}_{5}, \mathrm{~T}_{8}\right.$ and $\left.\mathrm{T}_{9}\right)$, the absence of GKN1 expression was instead observed.

Subsequently, based on our hypothesis, it was analyzed if the down-regulation of GKN1 was accompanied by an up-regulation of the transcription factor RUNX3 in the same human specimens. As reported in Figure 3, compared to non-tumoral tissues, RUNX3 was found always expressed in all tumoral tissues 


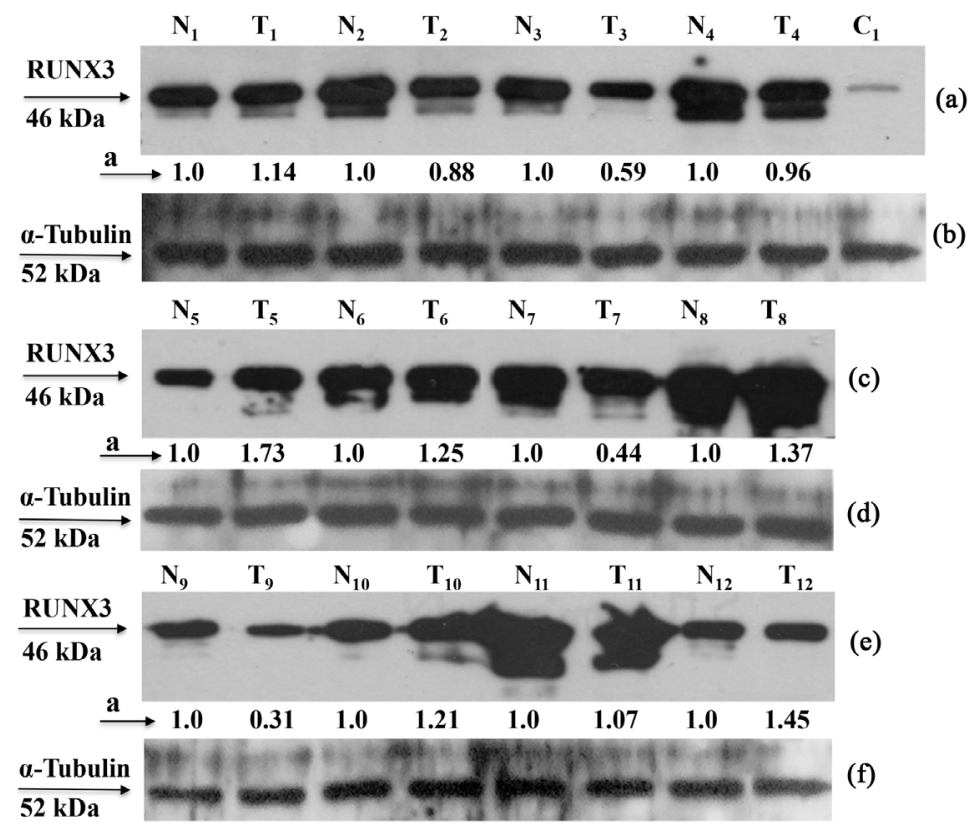

Figure 3. RUNX3 Expression levels in human gastric tissues. ((a), (c), and (e)) Expression levels of RUNX3 protein in non-tumoral $\left(\mathrm{N}_{1}-\mathrm{N}_{12}\right)$ and tumoral $\left(\mathrm{T}_{1}-\mathrm{T}_{12}\right)$ paired samples evaluated from the densitometry of RUNX3 bands normalized towards the corresponding densitometry of $\alpha$-tubulin bands ((b), (d), and (f)). Lane $C_{1}$. Human Raji cell line. (a) Ratio between RUNX3 band intensity and that of the corresponding $\alpha$-Tubulin.

(panels A, C, and E). $\alpha$-tubulin was used as control (panels B, D, and F). Compared to GKN1, RUNX3 was found to be up-regulated in 7 out of 12 tumoral tissues analyzed (58\%) (Figure 4). However, it must be considered that the densitometric ratios were only indicative because they were not statistically significant. Up-regulation of RUNX3 has been reported in primary and metastatic pancreatic [20], in early-onset gastric carcinomas [11], in basal cell carcinomas [21], in head and neck squamous cell carcinoma (HNSCC) tissues [25] and in ovarian cancer [19], thus suggesting an oncogenic property in cancer development [18] [19] [25].

\subsection{GKN1 Down-Regulation in GC Is Not Associated with RUNX3 on the GKN1 Promoter}

To investigate whether RUNX3 was involved in the inactivation of GKN1 gene, ChIP assays were performed. As already reported [7], for the Chip assay it was identified a $600 \mathrm{bp} G K N 1$ promoter region that was divided into three segments of about $160 \mathrm{bp}$ (A, B, and C). Compared with non-tumoral tissues, ChIP assays performed on these segments did not reveal a significant association of RUNX3 in tumoral tissues. In fact, as reported in Figure 5, the assay performed on five additional paired non-tumoral $\left(\mathrm{N}_{13}-\mathrm{N}_{17}\right)$ and tumoral $\left(\mathrm{T}_{13}-\mathrm{T}_{17}\right)$ specimens revealed variable results in chromatin immunoprecipitation of RUNX3 with the exception for the paired non-tumoral and tumoral specimens $\left(\mathrm{N}_{16}\right.$ and $\left.\mathrm{T}_{16}\right)$. This result strongly suggests the non-involvement of the transcription factor in the 


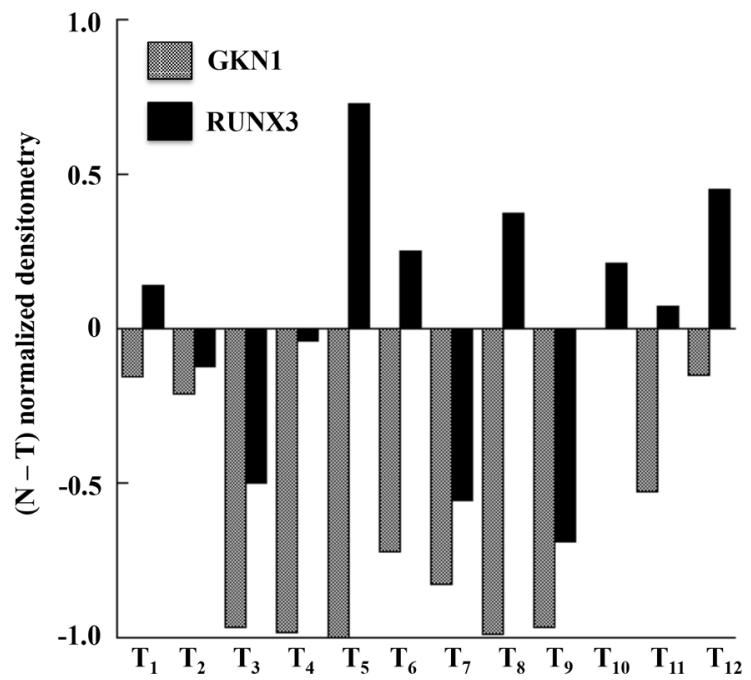

Figure 4. Comparison between GKN1 and RUNX3 expression levels of in the tumor tissues analyzed. The relative expression of GKN1 and RUNX3 was determined as the difference between WB band intensity of non-tumoral tissue and that of the corresponding tumoral one.
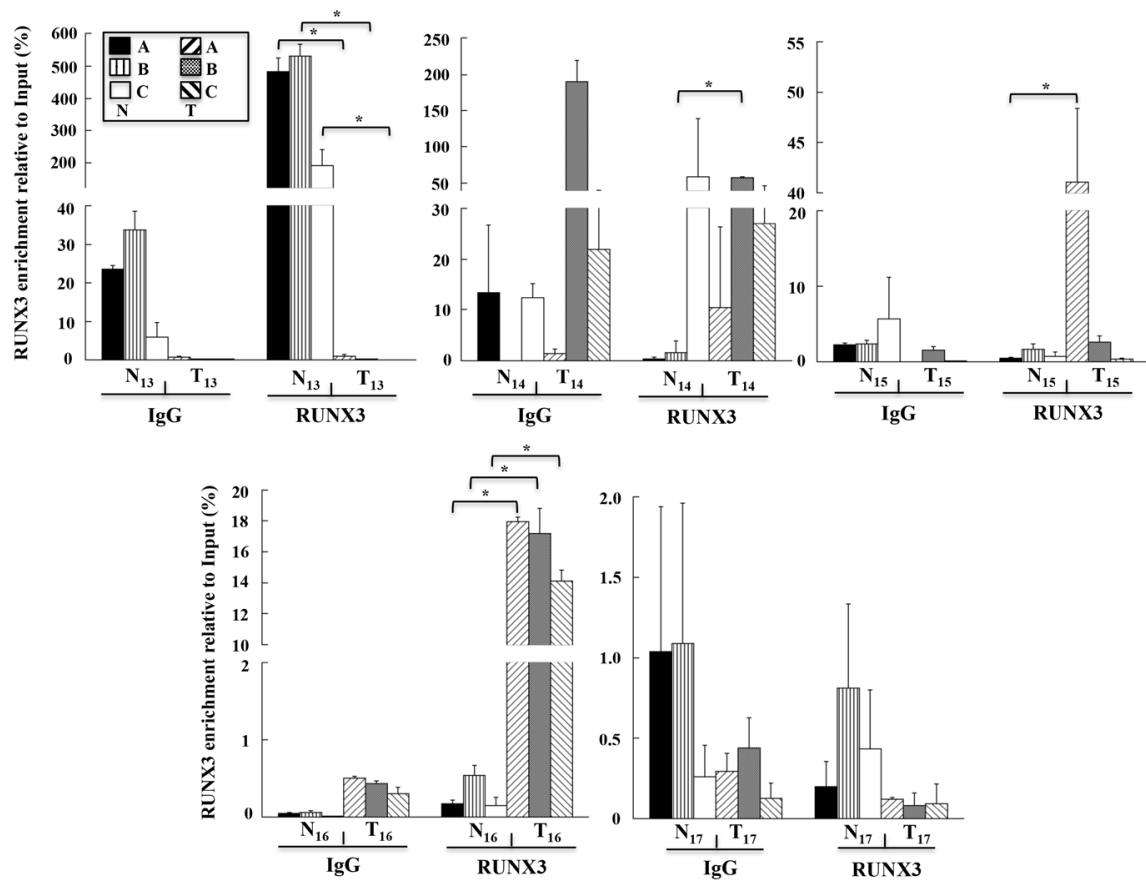

Figure 5. RUNX3 levels on human GKN1 gene promoter. ChIP assays performed on human non-tumoral $\left(\mathrm{N}_{13}-\mathrm{N}_{17}\right)$ and tumoral $\left(\mathrm{T}_{13}-\mathrm{T}_{17}\right)$ human gastric samples, respectively. RUNX3 enrichment relative to input is reported as $2 \Delta \mathrm{Ct} \cdot 100$, where $\Delta \mathrm{Ct}$ is the difference between Ct Input and Ct IP. All quantitative ChIP data were derived from three independent experiments, and for each experiment, qPCR was performed in triplicate. ${ }^{\star} p<0.05$, compared to corresponding control.

regulation of $G K N 1$ silencing in gastric cancer. In addition, the down-regulation of GKN1 in the specimens analyzed (Figure 6) was not correlated with the Chip results. 


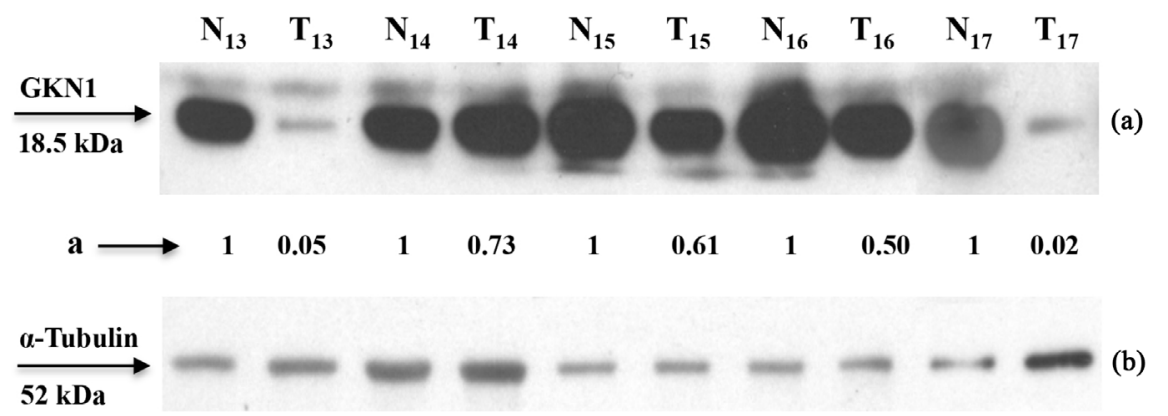

Figure 6. Expression levels of GKN1 in the gastric tissues used for Chip assay. (a) Western blot of tissue extracts analyzed in paired non-tumoral $\left(\mathrm{N}_{13}-\mathrm{N}_{17}\right)$ and tumoral $\left(\mathrm{T}_{13}\right.$ $\mathrm{T}_{17}$ ) human gastric samples, respectively, using mouse anti-GKN1 antibody $(\mathrm{Ab})$. a. Relative expression of GKN1 in sample tissues reported as band intensity ratio with that of the corresponding $\alpha$-Tubulin (b).

\section{Conclusions}

In the present study, we addressed the role of RUNX3 as a possible transcription factor involved in an epigenetic transcription complex that promotes silencing of $G K N 1$ gene expression. We aimed at identification of genes that contribute to GC development and progression and that might represent promising gene-targets for potential new therapies. Our experimental evidence shows that compared to non-tumoral tissues, the expression of RUNX3 in tumoral specimens of gastric tissues were not always alongside accompanied by the down-regulation of GKN1. The non-involvement of RUNX3 in GKN1 gene silencing was also confirmed by ChiP assay. In fact, no recruitment of RUNX3 on GKN1 gene promoter was significantly observed in assays performed on tumoral samples compared to non-tumoral ones. Considering the quite abundant expression levels of RUNX3 in non-tumoral samples and its up-regulation in several tumors, the data obtained confirm the actual view that RUNX3 is not a tumor suppressor and support its potential oncogenic role in GC.

\section{Acknowledgements}

The authors declare that they have no conflict of interest. The authors thank Dr. G. de Dominicis, Hospital Cardarelli, Naples, Italy, for tissue histopathological classification and immunohistochemistry. This work was supported by funds from Programmi di Ricerca Scientifica di Rilevante Interesse Nazionale (2012CK5RPF_004), PON Ricerca e Competitività 2007-2013 (PON01_02782) and POR Campania FSE 2007-2013, Project CRÈME.

\section{Conflicts of Interest}

The authors declare that there is no conflict of interest.

\section{Disclosure Statement}

Nothing to declare. 


\section{Authors' Contributions}

CSDS and FA were involved in Chip assays, AF performed qRT-PCR analysis and statistical evaluation, GM was involved in WB and cell extract preparation, MDP and AN take care of patient recruitment, ER was involved in the preparation of a draft manuscript, PA was involved in the reading and approval of the final manuscript.

\section{References}

[1] Rippa, E., Altieri, F., Di Stadio, C.S., Miselli, G., Lamberti, A., Federico, A., Quagliariello, V., Papale, F., Guerra, G. and Arcari, P. (2015) Ectopic Expression of Gastrokine 1 in Gastric Cancer Cells Up-Regulates Tight and Adherens Junction Proteins Network. Pathology Research and Practice, 211, 577-583.

https://doi.org/10.1016/j.prp.2015.04.008

[2] Toback, F.G., Walsh-Reitz, M.M., Musch, M.W., Chang, E.B., Del Valle, J., Ren, H., Huang, E. and Martin, T.E. (2003) Peptide Fragments of AMP-18, a Novel Secreted Gastric Antrum Mucosal Protein, Are Mitogenic and Motogenic. American Journal of Physiology Gastrointestinal and Liver Physiology, 285, G344-G353. https://doi.org/10.1152/ajpgi.00455.2002

[3] Walsh-Reitz, M.M., Huang, E.F., Musch, M.W., Chang, E.B., Martin, T.E., Kartha, S. and Toback, F.G. (2005) AMP-18 Protects Barrier Function of Colonic Epithelial Cells: Role of Tight Junction Proteins. American Journal of Physiology Gastrointestinal and Liver Physiology, 289, G163-G171. https://doi.org/10.1152/ajpgi.00013.2005

[4] Nardone, G., Martin, G., Rocco, A., Rippa, E., La Monica, G., Caruso, F. and Arcari, P. (2008) Molecular Expression of Gastrokine 1 in Normal Mucosa and in Helicobacter pylori Related Preneoplastic and Neoplastic Gastric Lesions. Cancer Biology and Therapy, 7, 1890-1895. https://doi.org/10.4161/cbt.7.12.6936

[5] Oien, K.A., McGregor, F., Butler, S., Ferrier, R.K., Downie, I., Bryce, S., Burns, S. and Keith, W.N. (2004) Gastrokine 1 Is Abundantly and Specifically Expressed in Superficial Gastric Epithelium, Down-Regulated in Gastric Carcinoma, and Shows High Evolutionary Conservation. The Journal of Pathology, 203, 789-797. https://doi.org/10.1002/path.1583

[6] Rippa, E., La Monica, G., Allocca, R., Romano, M.F., De Palma, M. and Arcari, P. (2011) Overexpression of Gastrokine 1 in Gastric Cancer Cells Induces Fas-Mediated Apoptosis. Journal of Cellular Physiology, 226, 2571-2578. https://doi.org/10.1002/jcp.22601

[7] Altieri, F., Di Stadio, C.S., Federico, A., Miselli, G., De Palma, M., Rippa, E. and Arcari, P. (2017) Epigenetic Alterations of Gastrokine 1 Gene Expression in Gastric Cancer. Oncotarget, 810, 16899-16911. https://doi.org/10.18632/oncotarget.14817

[8] Otto, F., Lübbert, M. and Stock, M. (2003) Upstream and Downstream Targets of RUNX Proteins. Journal of Cellular Biochemistry, 89, 9-18.

https://doi.org/10.1002/jcb.10491

[9] Ito, Y. (2004) Oncogenic Potential of the RUNX Gene Family: "Overview". Oncogene, 23, 4198-4208. https://doi.org/10.1038/sj.onc.1207755

[10] Lotem, J., Levanon, D., Negreanu, V. and Groner, Y. (2013) The False Paradigm of RUNX3 Function as Tumor Suppressor in Gastric Cancer. Journal of Cancer Therapy, 4, 16-25. https://doi.org/10.4236/jct.2013.41A003 
[11] Carvalho, R., Milne, A.N., Polak, M., Corver, W.E., Offerhaus, G.J. and Weterman, M.A. (2005) Exclusion of RUNX3 as a Tumour-Suppressor Gene in Early-Onset Gastric Carcinomas. Oncogene, 24, 8252-8258. https://doi.org/10.1038/sj.onc.1208963

[12] Friedrich, M.J., Rad, R., Langer, R., Voland, P., Hoefler, H., Schmid, R.M., Prinz, C. and Gerhard, M. (2006) Lack of RUNX3 Regulation in Human Gastric Cancer. The Journal of Pathology, 210, 41-146. https://doi.org/10.1002/path.2042

[13] Abnet, C.C., Freedman, N.D, Hu, N., Wang, Z., Yu, K., Shu, X.O., Yuan, J.M., Zheng, W., Dawsey, S.M., Dong, L.M., Lee, M.P., Ding, T., Qiao. Y.L., Gao Y.T., Koh, W.P., Xiang, Y.B., Tang, Z.Z., Fan, J.H., Wang, C., Wheeler, W., Gail, M.H., Yeager, M., Yuenger, J., Hutchinson, A., Jacobs, K.B., Giffen, C.A., Burdett, L., Fraumeni, J.F. Jr, Tucker, M.A., Chow, W.H., Goldstein, A.M., Chanock, S.J. and Taylor, P.R. (2010) A Shared Susceptibility Locus in PLCE1 at 10q23 for Gastric Adenocarcinoma and Esophageal Squamous Cell Carcinoma. Nature Genetics, 42, 764-767. https://doi.org/10.1038/ng.649

[14] Sakamoto, H., Yoshimura, K., Saeki, N., Katai, H., et al. (2008) Genetic Variation in PSCA Is Associated with Susceptibility to Diffuse-Type Gastric Cancer. Nature Genetics, 40, 730-740. https://doi.org/10.1038/ng.152

[15] Shi, Y., Hu, Z., Wu, C., Dai, J., Li, H., Dong, J., Wang, M., Miao, X., Zhou, Y., Lu, F., Zhang, H., Hu, L., Jiang, Y., Li, Z., Chu, M., Ma, H., Chen, J., Jin, G., Tan, W., Wu, T., Zhang, Z., Lin, D. and Shen, H. (2011) A Genome-Wide Association Study Identifies New Susceptibility Loci for Non-Cardia Gastric Cancer at 3q13.31 and 5p13.1. Nature Genetics, 43, 1215-1218. https://doi.org/10.1038/ng.978

[16] Wang, L.D., Zhou, F.Y., Li, X.M., et al. (2010) Genome-Wide Association Study of Esophageal Squamous Cell Carcinoma in Chinese Subjects Identifies Susceptibility Loci at PLCE1 and C20orf54. Nature Genetics, 42, 759-763. https://doi.org/10.1038/ng.648

[17] Hu, S.L., Huang, D.B., Sun, Y.B., Wu, L., Xu, W.P., Yin, S., Chen, J., Jiang, X.D. and Shen, G. (2011) Pathobiologic Implications of Methylation and Expression Status of RUNX3 and CHFR Genes in Gastric Cancer. Medical Oncology, 28, 447-454. https://doi.org/10.1007/s12032-010-9467-6

[18] Kudo, Y., Tsunematsu, T. and Takata, T. (2011) Oncogenic Role of RUNX3 in Head and Neck Cancer. Journal of Cellular Biochemistry, 112, 387-393.

https://doi.org/10.1002/jcb.22967

[19] Lee, C.W., Chuang, L.S., Kimura, S., Lai, S.K., Ong, C.W., Yan, B., Salto-Tellez, M., Choolani, M. and Ito, Y. (2011) RUNX3 Functions as an Oncogene in Ovarian Cancer. Gynecologic Oncology, 122, 410-417.

https://doi.org/10.1016/j.ygyno.2011.04.044

[20] Li, J., Kleeff, J., Guweidhi, A., Esposito, I., Berberat, P.O., Giese, T., Büchler, M.W. and Friess, H. (2004) RUNX3 Expression in Primary and Metastatic Pancreatic Cancer. Journal of Clinical Pathology, 57, 294-299. https://doi.org/10.1136/jcp.2003.013011

[21] Salto-Tellez, M., Peh, B.K., Ito, K., Tan, S.H., Chong, P.Y., Han, H.C., Tada, K., Ong, W.Y., Soong, R., Voon, D.C. and Ito, Y. (2006) RUNX3 Protein Is Overexpressed in Human Basal Cell Carcinomas. Oncogene, 25, 7646-7649. https://doi.org/10.1038/sj.onc.1209739

[22] The American Joint Committee on Cancer (2010) AJCC Cancer Staging Manual and the Future of TNM. 7th Edition, Annals of Surgical Oncology, 17, 1471-1474. 
[23] Di Stadio, C.S., Altieri, F., Miselli, G., Elce, A., Severino, V., Chambery, A., Quagliariello, V., Villano, V., de Dominicis, G., Rippa, E. and Arcari, P. (2016) AMP18 Interacts with the Anion Exchanger SLC26A3 and Enhances Its Expression in Gastric Cancer Cells. Biochimie, 121, 151-160. https://doi.org/10.1016/j.biochi.2015.12.010

[24] Federico, A., Pallante, P., Bianco, M., Ferraro, A., Esposito, F., Monti, M., Cozzolino, M., Keller, S., Fedele, M., Leone, V., Troncone, G., Chiariotti, L., Pucci, P. and Fusco, A. (2009) Chromobox Protein Homologue 7 Protein, with Decreased Expression in Human Carcinomas, Positively Regulates E-Cadherin Expression by Interacting with the Histone Deacetylase 2 Protein. Cancer Research, 69, 7079-7087. https://doi.org/10.1158/0008-5472.CAN-09-1542

[25] Tsunematsu, T., Kudo, Y., Iizuka, S., Ogawa, I., Fujita, T., Kurihara, H., Abiko, Y. and Takata, T. (2009) RUNX3 Has an Oncogenic Role in Head and Neck Cancer. PLoS ONE, 4, e5892. https://doi.org/10.1371/journal.pone.0005892

\section{Abbreviations}

ChIP, chromatin immunoprecipitation; GC, gastric cancer; GKN1, gastrokine 1; HDAC, histone deacetylase; H3K9triMe, trimethylation of Histone 3 at lysine 9; IM, intestinal metaplasia; TSA, trichostatin A; TSG, tumor suppressor gene; SUV39H1, Histone-lysine N-methyltransferase 